\title{
The Background and Development of the Youth Leadership Education in China
}

\author{
Chao Yufang \\ College of Business Administration \\ Qilu University of technology, \\ Jinan, China \\ chaochuwen@sina.com
}

\author{
Li Yuee \\ College of Business Administration \\ Qilu University of technology, \\ Jinan, China \\ lye@spu.cn.com
}

\begin{abstract}
In-depth analysis of the background of the youth leadership education, is conducive to better coordination of resources, to co-ordinate the efforts of all parties to promote this work. The background of the current youth leadership education mainly include: enhanced the uncertainty of the economic and social development; social diversification trend intensified; competition; improve the transformation cost; knowledge becomes the key resources of the development organization; organizational boundaries are broken, team and project operation mechanism highlights the role; material developed, democratic consciousness of human enhancement. At the same time, the efficiency of adult leadership education is low, which makes people pay more and more attention to the youth leadership education. In the development of leadership education for adolescents should be the scientific understanding of essence of educational leadership, government and education institutions at all levels, to fully understand the leadership education is closely related to national sustainable development and national competitiveness, leadership education should be for the public, from knowledge education to change the development ability.
\end{abstract}

Keywords-Leadership education; change; the youth; background

\section{INTRODUCTION}

Since the 80's in twentieth Century, the United States has begun to attach importance to the youth leadership education; the relevant leadership education development course has become an important part of the education system of American University. Subsequently, the youth leadership education activities have attracted the attention of European countries, the international well-known universities have opened leadership courses, such as the University of Oxford, etc.. 2006, the American future of Higher Education Commission submitted the report (A Test of Leadership: Charting the Future of U.S. Higher Education)to plan the next 10 to 20 years of the United States higher education. The report has repeatedly referred the importance of leadership education. In 2010, the president of Harvard University, Yale University, Oxford University and other famous universities talk about education training objectives to train students to be leader in the conference of university presidents held in Shanghai.

For China, Leadership education is an exotic, and launched time is short. In view of the importance of Youth Leadership Education, china universities are also held the leadership

Supported by Natural Science Foundation of Shandong Province (ZR2013GM008), China courses in succession. However, the in-depth and systematic analysis of the leadership education is lack. This leads to the youth leadership education in China just shout loudly, but do less. Therefore, in-depth and systematic analysis international youth leadership education to carry out the background characteristics, is conducive to the comprehensive understanding of youth leadership education and development of the inherent laws, a deep understanding of youth leadership education significance, necessity and important value.

\section{TIME BACKGROUND OF YOUTH LEADERSHIP EDUCATION}

\section{A. Growing Uncertainty of Social and Economic Development}

Since the 1980 's, science and technology mainly on information technology has been developed rapidly; economic globalization is increasing too; and organizations more closely linked and mutual dependence more improve [1].

In aspect of social and political environment, since the 1970 's, the international situation and the overall trend are easing, and the cold war has end too. But there has been no fundamental change in the overall pattern of international relations, development between the north and the South and between the rich and the poor still is expanding, the conflicts continuously rise due to ethnic, religious and other problems. In addition, with the rise of emerging countries and the development of the EU, the world presents a trend of multi polarization. The development of multi polarization also leads to exacerbate the contradictions and conflicts between nations, especially in the wake of the financial crisis, the international contradictions deepen, trade friction intensified, heating up the Cold War mentality, currency and trade wars happened frequently.

The uncertainty of economic environment and social environment increases people's anxiety. People have higher expectations to leaders, and further focus on the leadership education. As $<\mathrm{A}$ Test of Leadership: Charting the Future of U.S. Higher Education>said: in the world of tomorrow, a national source of wealth to the national education, attract and sustain the ability of citizens to wise and faster learning[2]. 


\section{B. Trend of Diversification of Social development}

Economic globalization is not only that the factors of production across borders, free flowing in the global range and in various countries, also brought international economy, politics, society, culture, education deepening exchanges and fusion. This makes all kinds of organizations have to face the leadership and management of multiple cultures. This leads to the more demand for leadership education and development.

On the other hand, with the development of globalization, state more open, the process of social democracy speed up, human spiritual civilization more improvement, diversification has become is the inevitable trend of the development of modern society. Not only the whole human values are diversified development trend, life style is also constantly changing, the inter-generational differences are becoming more and more obvious. Especially after 1980's, the organization staff's diversified development trend is more obvious. Workforce diversity, pluralistic culture and values are obvious too. This undoubtedly cause higher demand on leadership, how to affect different colleagues, partners have become a major challenge to the leaders of various organizations. In contemporary China, the diversification of values is a common fact; all kinds of organizations are facing the problem of the leadership and management to new generation.

\section{Organizational Change and Innovation}

Environmental dynamism is constantly improving, leading the organization to improve the ability to change. At the same time, with the development of economic integration, human needs and the development of technology and resource depletion and other reasons, all kinds of organizations are facing fierce competition. If cannot adapt to environmental changes, or do not have the corresponding ability to compete, it will be mercilessly eliminated. This highly competitive environment has brought tremendous survival and development pressure to organization. The organization must strengthen entrepreneurship and change.

How to guide the organization innovation and reform is a difficult problem in front of all kinds of organizational leaders. To lead the organization to achieve innovation and transformation in the highly competitive and highly competitive environment, it is necessary to improve the leadership of the organization. At the same time, improve leadership, and hope that the leader play greater roles in change and innovation process become the general needs of the organization and the instinct found.

\section{Higher Failure Cost of Innovation and Change}

In the present era, the factors affecting the organization are more and more, the organization is also increasingly complex, a little careless, it may lead to failure.

At the same time, the scale of the current organization is increasing, and the mutual dependence between the organizations is increasing, and the impact of innovation and change is also increasing. Whether the leader's decision is correct or not, it is a matter of survival and development of the organization. And improve the organizational innovation success rate, not only require the leader to grasp the correct direction, the correct decision must also be adopting the correct method to unite the power and passion of the members of the organization.

\section{E. Knowledge Become Key Resource of Organization Development}

Society is experiencing the development process from the agricultural society to the industrial society to the knowledge economy society. Knowledge economy is the main economic development mode. In this mode of development, the key role of people is more prominent. Person is the main body of knowledge creation. Wu must play their subjective initiative and potential.

At the same time, the ubiquitous knowledge network is becoming more and more prominent, and the information network has promoted the transmission and sharing of knowledge. It has become an important basis for the formation and development of knowledge society [3]. Under this background, the social form is increasingly complex and changeable, and the traditional social organization and its active boundary are "melting" [4]

Knowledge creation and innovation is no longer the prerogative of minorities patent, everyone can become the main body of knowledge innovation, and everyone has the creativity of the ultimate right to speak and the right to participate in. So, the original mode of the functions of management and authoritarian leadership model is no longer applicable, must improve the leadership to implement effective leadership and management.

\section{F. Team and Project Oriented Operation Mode}

Due to the complexity of the work, especially in the modern society, any work is a systematic project, any individual cannot be done alone and need to many people work together, therefore often need to team composed of experts..[6] In addition, because of the innovative activities have one-time, unique and non-deterministic and other fundamental characteristics, so the management of innovation activities in essence is a kind of project management [5]. at the same time, enterprises want to get better economic value added, must put their own resources in those engaged in creative and not rules of manufacturing and business aspects[6]. These make the project oriented model to be the operation mode of all kinds of organizations.

With the break of the inner boundary of the organization, the traditional organization is distinct, and the system of division of labor is also broken. There is no obvious relationship between the level of the staff, the leadership and the leadership role of the frequent changes. In this case, the influence is not completely from the powers. Knowledge, information, personality charm beyond the positions of authority in the sphere of influence, all members of the organization leadership proposed higher requirements, leadership education naturally become the urgent need for all kinds of organizations.

\section{G. Human dependence on the organization reduced}

With the development of economy, the increase of material wealth, the dependence of the individual to the material is decreasing, and the dependence of the organization is also 
decreasing. The development of material civilization promoted the improvement of the human spirit civilization, human beings are more and more free, and the demand for democracy is increasingly strong. This leads to rely on traditional administrative orders; material reward has been difficult to influence members of the organization. The traditional influence and the change of other people's skills and the mode of the loss of the role, is bound to lead to a strong demand for leadership education.

It should be noted that the leadership education is the inevitable development of human, social and economic development, is bound to be an internal demand. The change of the environment makes all kinds of organizations begin to attach importance to the development of leadership education, and invest a lot of resources for the development of leadership education. Of course, this is just a necessary condition for the development of leadership education for teenagers, rather than a sufficient condition. If the adult leadership education development is fruitful, there is no need to adolescent leadership education and development.

\section{THE REALITY AND PREDICAMENT OF ADULT LEADERSHIP EDUCATION}

Development so far, the leadership science has only a hundred years of history. Within 100 years, the leadership theory development is a hundred flowers bloom; a hundred schools contend, from the theory of leadership trait to theory of leadership behavior to situational leadership theory and today's transformational leadership, visionary leadership, the cross culture leadership. Leadership theory research so get attention, it also explain the need to improve the ability from one side. But leadership education practice as if plays a big joke with people. F.E.Fiedler's study in the 1970's found that a lot of adult leadership education training has little effect and has little contribution to the organizational performance. F.E.Fiedler's research has caused the leadership theory people shock, also started the situation leadership theory research. Along with the thorough research, people found that the situation leadership theory looks very beautiful, but in practice it is difficult to play a role. The key reason is that it is difficult to change the behavior of adults. It is almost impossible to change a person's behavior without the appropriate personality traits [7].

Recently, Kulun\&We Avolio (2009), Avolio, Reichard, etc. (2009) and Rotundo etc.. The research shows that the adult's leadership education has certain effect, but the effect is low [8]. Susan Elaine and Murphy (2011) believes that there may be two reasons, one is the most ability or quality development occurred in the early; the second is leadership development is self-reinforcing properties, should long leadership education development time, and focus on early development[9]. Research progress and reflection on adult leadership education and performance research makes people begin to realize importance and necessity of the youth leadership education and development. As is known to all, the personality characteristics of adults have been formed, it is difficult to change or shape. The young people are in the stage of personality development, mature stage, the personality characteristics of the plasticity is strong $[10,11,12]$.
Follow this logic; the researchers will naturally lead to the development of the youth leadership education research, starting to focus on the research and practice of youth leadership education. Many scholars (Ligon, 2008; Day, Harrison, \& Haplin, 2009; Murphy, 2011; Wise, Valaida, 2012 etc.) emphasize that we should pay attention to the early leadership education development; Ligon et al. (2008) pointed out that the earlier the leadership development, the earlier the opportunity to revise the corresponding problems. Lu Deping (2008), Martinek, Schilling and Hellison (2006), Wu Fengli (2007) agreed that the youth is a very important period of life transition period. During this period, youth and gradually establish a personality, and willing to try new things to learn and master the leadership, including all important life skills, adolescence is the best time and critical timing to leadership development. And with the youth leadership education research and development progress, the corresponding practice develops rapidly; the United States has more than 600 universities focus on students to develop leadership in the classroom teaching, extracurricular activities and projects.

\section{THE FUTURE DEVELOPMENT OF CHINESE YOUTH LEADERSHIP EDUCATION}

As a rising developing country, China has become the world's second largest economy, the international status is rising, and the influence is growing. But we must see that China is facing the crisis, is in a new starting point for comprehensive deepening reform of history today. China is too experiencing unprecedented resource constraints, environmental constraints, institutional and mechanism constraints, external constraints, etc.. International and domestic conflicts related to cross; the challenges and difficulties interweave together, the upgrading of the industrial structure, enterprise restructuring and development, the interests of all sectors of society friction, philosophy and viewpoint of value conflict, ideological turbulence. Those all put forward challenge and test for China development and Chinese dream. China's ability to maintain the appropriate is very important in the future. The development of the western countries provides a good reference for China. China should pay attention to the youth leadership education.

\section{A. Understand the Essence of Leadership Education}

Different social background, cultural tradition and institutional framework, the understanding of leadership is different. Different cognitive leads to leadership education mode and way of natural difference.

Influenced by traditional Chinese culture, Chinese people often think leadership as leaders or leadership positions, and take the leadership as only the ability needed of the leader or occupy leadership positions. This kind of narrow understanding, will inevitably lead to the development of leadership education, and effect the popularization of people's participation.

Many people naturally think that they are no leader; they need not learn leadership education and training courses. Therefore, it must be scientific, comprehensive and systematic exposition show to people the connotation and essence of leadership, and guide people to scientific and theoretical 
understand the scientific the leadership, guided people view change from the position to the ability.

\section{B. Fully Understanding Importance of Leadership Education}

The national government and all levels of educational institutions all should fully understand the relationship between leadership education to the country's sustainable development and national competitiveness.

By the Chinese traditional culture, leadership education has always been ignored, as a weak link in China's education. So far, especially in the era of knowledge economy and reform, the leadership education is not only related to the competitiveness of all kinds of organizations, but also related to the sustainable development and competitiveness of the country. Government and all educational institutions should realize that the leadership resources have become strategic, scarce resources, and investment resources for leadership education.

\section{Popularization of Leadership Education}

In china, leadership education is often looking as work that train leader. But the leadership education should face all people in today. So, the china government and all education organization fully aware that the modern leadership education development is not for some "elite", is for the public education development.

As mentioned before, the current and future development of the team, everyone needs leadership; everyone needs to lead the process. This requires that we break the original for leader or potential leader of the education development of the narrow understanding should be the leadership education development to the general public, in order to adapt to the need of the development of the future state and all kinds of organizations.

So, in the future, the leadership education courses should face all the youth. All school, especially university all should establish the youth leadership education programmers. Though facing the all people, the youth leadership can be developed.

\section{Recognizing the scientific nature, continuity and urgency of carrying out the leadership education}

Today, leadership education development is very scientific, sustainable and urgent in china. China must take full recognition on this. The formation of leadership is more complicated, especially in its own law. It also determines the development of leadership education must emphasize science, not blindly, otherwise, cause endless trouble to future. Once again, from the practice of foreign leadership education development, the formation of leadership has a sustained, is through the people's life.

China must realize this point: the leadership education development runs through the various stages of development. In addition, we must see the urgency of the development of youth leadership education. Whether it is the study of the development of the youth leadership education, or the practice of the education development, our country is in the initial stage.
This is far from meeting the needs of social and economic development and economic development in our country.

\section{E. Education from knowledge education to ability development}

Although China advocates quality education for many years, the practical effect is still unsatisfactory. From the perspective of leadership education practice, the West focused on the development of leadership through practice or action. This is what China must emphasize in the development of leadership education. Leadership education development should be based on the ability to be a leader, not knowledge, both in childhood and adolescence.

\section{CONCLUSION}

Today, China needs a lot of leadership resources. But time that china launches the youth leadership education is short. Chin must take full recognition on the youth leadership education, put resources on the work.

\section{REFERENCES}

[1] Wang zhongtuo. Knowledge network in Ubiquitous Network Society. Chin journal of information system, vol.1.no.1.cet.2007:1-7

[2] Song G. and Cornford T. Mobile Government: Towards a Service Paradigm, in Proceedings of the 2nd International Conference on eGovernment, University of Pittsburgh, USA. 2006: 208-218

[3] Song G., Zhang N. and Meng Q. Innovation 2.0 as a Paradigm Shift: Comparative Analysis of Three Innovation Modes, in Proceedings of the 2009 International Conference on Engineering Management and Service Sciences, Beijing, China. 2009

[4] ].Kimball Fisher. Mareen Duncan Fisher. The Distributed Mind Achieving High Performance through the Collective Intelligence of Knowledge Team. The Fisher Group, Inc. American Management Association International. New York, NY 10019.

[5] Qi Anbang, Yang Yuwu, Liao Yuanhon, Zhai Lei. On Project Oriented Organization and Society for the Knowledge Economy and the Construction of Innovative Country, Science of Science and Management of S.\& T. no.4.2006:70-76

[6] Ding Ronggui, Sun Yanan, Lv Guanzhu. Research on Organziational Mechanism for Project-oriented, Journal of Shandong University(Philosophy and Social Sciences,no.6.2008:113-114

[7] Lu Deping. The germination and formation of the Youth Leadership. China Youth Study, 5.2008:10-15.

[8] Sui Mingfang. A study on the leadership training of primary and middle school students in the United States of America. Capital Normal University. 2007

[9] Susan Elaine Murphy, Stefanie K. Johnson, The benefits of a long-lens approach to leader development: Understanding the seeds of leadership, The Leadership Quarterly, 22 (2011):459-470;

[10] Arvey, R., Chaturvedi.S, Examining the genetic basis of leadership. In S E. Murphy, \& R. J. Reichard (Eds.), Early development and leadership: Building the next generation of leaders New York: Psychology Press/Routledge. 2011:59-69;

[11] Recchia, S. Preschool leaders in the early childhood classroom. In S. E. Murphy, \& R. J. Reichard (Eds.), Early development and leadership: Building the next generation of leaders (pp. 39-58). New York: Psychology Press/Routledge. 2011:39-58;

[12] Tracy Leanne, Relationship between Leadership Traits and Activity Participation among Madison Plains High School Students. the Ohio State University. 